\title{
A NOTE ON THE PAPER OF BREAZ AND GÜNEY
}

\author{
SERAP BULUT
}

Abstract. In this note, we generalize the Theorem 1 and Theorem 3 in [2]. Furthermore, we consider the strongly starlikeness and strongly convexity classes of the analytic functions and two integral operators.

Mathematics subject classification (2000): $30 \mathrm{C} 45$.

Keywords and phrases: Integral operator, Analytic functions, Starlike functions, Convex functions, Complex order.

\section{REFERENCES}

[1] D. Breaz and N. Breaz, Two integral operators, Studia Univ. Babeş-Bolyai Math. 47 (2002), no. 3, 13-19.

[2] D. BReAZ And H. Ö. Guney, The integral operator on the classes $\mathscr{S}_{\alpha}^{*}(b)$ and $\mathscr{C}_{\alpha}(b)$, J. Math. Ineq. 2 (2008), no. 1, 97-100.

[3] D. Breaz, S. Owa, And N. Breaz, A new integral univalent operator, Acta Univ. Apulensis Math. Inform. 16 (2008), 11-16.

[4] B. A. Frasin, Family of analytic functions of complex order, Acta Math. Acad. Paedagog. Nyházi. (N.S.) 22 (2006), 179-191. 